\title{
Correlates of virulence in a frog-killing fungal pathogen: evidence from a California amphibian decline
}

\author{
Jonah Piovia-Scott ${ }^{1}$, Karen Pope ${ }^{2}$, S Joy Worth ${ }^{3}$, Erica Bree Rosenblum ${ }^{4}$, Thomas Poorten ${ }^{4}$, \\ Jeanine Refsnider ${ }^{4}$, Louise A Rollins-Smith ${ }^{5,6,7}$, Laura K Reinert ${ }^{5,6}$, Heather L Wells ${ }^{7}$, \\ Dan Rejmanek ${ }^{3}$, Sharon Lawler ${ }^{8}$ and Janet Foley ${ }^{3}$ \\ ${ }^{1}$ Department of Biology, University of California, Riverside, CA, USA; ${ }^{2}$ Pacific Southwest Research Station, \\ United States Forest Service, Arcata, CA, USA; ${ }^{3}$ Department of Veterinary Medicine and Epidemiology, \\ University of California, Davis, CA, USA ${ }^{4}$ Department of Environmental Science, Policy, and Management, \\ University of California, Berkeley, CA, USA; ${ }^{5}$ Department of Pathology, Microbiology and Immunology, \\ Vanderbilt University School of Medicine, Nashville, TN, USA; ${ }^{6}$ Department of Pediatrics, Vanderbilt \\ University School of Medicine, Nashville, TN, USA; ${ }^{7}$ Department of Biological Sciences, Vanderbilt \\ University, Nashville, TN, USA and ${ }^{8}$ Department of Entomology, University of California, Davis, CA, USA
}

\begin{abstract}
The fungal pathogen Batrachochytrium dendrobatidis $(B d)$ has caused declines and extinctions in amphibians worldwide, and there is increasing evidence that some strains of this pathogen are more virulent than others. While a number of putative virulence factors have been identified, few studies link these factors to specific epizootic events. We documented a dramatic decline in juvenile frogs in a Bd-infected population of Cascades frogs (Rana cascadae) in the mountains of northern California and used a laboratory experiment to show that $B d$ isolated in the midst of this decline induced higher mortality than $B d$ isolated from a more stable population of the same species of frog. This highly virulent $B d$ isolate was more toxic to immune cells and attained higher density in liquid culture than comparable isolates. Genomic analyses revealed that this isolate is nested within the global panzootic lineage and exhibited unusual genomic patterns, including increased copy numbers of many chromosomal segments. This study integrates data from multiple sources to suggest specific phenotypic and genomic characteristics of the pathogen that may be linked to disease-related declines.
\end{abstract}

The ISME Journal (2015) 9, 1570-1578; doi:10.1038/ismej.2014.241; published online 16 December 2014

\section{Introduction}

Disease impacts are traditionally viewed as an interaction between characteristics of host, pathogen and environment (the 'epidemiologic triangle'). Many epizootic events are driven by the emergence of hyper-virulent strains of a pathogen (Lipsitch et al., 2003; LaDeau et al., 2007; Smith et al., 2009). In these cases, pathogen characteristics overshadow the effects of hosts and environment. Understanding the genetic and physiological changes in a pathogen that contribute to hyper virulence requires an integrated research approach that links carefully designed virulence assays and detailed studies of putative virulence factors to specific epizootic events.

Batrachochytrium dendrobatidis $(B d)$ is an emerging fungal pathogen that has been implicated in

Correspondence: J Piovia-Scott, Department of Biology, University of California, Riverside, CA 92521, USA.

E-mail: jonahps@ucr.edu

Received 4 June 2014; revised 6 November 2014; accepted 9 November 2014; published online 16 December 2014 epidemics and extinctions of amphibians worldwide (Berger et al., 1998; Lips et al., 2006; Wake and Vredenburg, 2008). Bd causes the disease chytridiomycosis, and its effect on amphibians has been described as "the most spectacular loss of vertebrate biodiversity due to disease in recorded history' (Skerratt et al., 2007). There is considerable variation in the effect of $B d$ on amphibian populations, ranging from rapid extirpation of the host to longterm coexistence of host and pathogen (Kilpatrick et al., 2010). The effect of $B d$ on amphibian hosts can be influenced by environmental factors, most notably temperature (for example, Kriger et al., 2007; Richards-Zawacki, 2010) and host susceptibility (reviewed in Fisher et al., 2009b). In addition, several laboratory experiments document variation in virulence between different $B d$ isolates (Berger et al., 2005; Retallick and Miera, 2007; Fisher et al., 2009a; Farrer et al., 2011; Gahl et al., 2012).

Recently there have been significant advances in our understanding of the mechanisms underlying $B d$ virulence (which we define as the host's 
pathogen-induced loss of fitness). First, whole genome sequencing and expression studies have led to new insights into the phylogenetics and functional genomics of $B d$. Specifically, genomic approaches identified distinct lineages within $B d$, including a global panzootic lineage (GPL) that contains many of the most deadly $B d$ isolates (Farrer et al., 2011; Rosenblum et al., 2013); such analyses have also identified gene families that may have a role in $B d$ virulence (for example, Joneson et al., 2011; Rosenblum et al., 2012; Farrer et al., 2013). Second, specific $B d$ traits have been linked to virulence, including zoospore production (Langhammer et al., 2013), zoosporangium size (Fisher et al., 2009a) and the ability to inhibit the growth of immune cells (Fites et al., 2013). Here, we integrate field surveys of host and pathogen dynamics with a laboratory exposure experiment that provides a rigorous virulence assay, in vitro assays of putative virulence traits and genomic characterization of $B d$ isolates, thereby linking phenotypic and genomic virulence mechanisms to an amphibian decline in the field.

Our study focuses on the Cascades frog (Rana cascadae), a montane species that ranges from southern Canada to northern California. Laboratory experiments indicate that post-metamorphic $R$. cascadae are susceptible to Bd (Garcia et al., 2006), and dramatic declines in California's Cascade Mountains are thought to be caused by $B d$ (Fellers et al., 2008; Pope et al., 2014). However, $B d$ is widespread in the range of $R$. cascadae (Adams et al., 2010; Piovia-Scott et al., 2011) and declines are not universal (Pearl et al., 2009), suggesting that there is important variation in the effect of $B d$ on populations of this host amphibian. One study suggested that juvenile $R$. cascadae have higher $B d$ prevalence than other life stages (Piovia-Scott et al., 2011), and many affected populations experience repeated recruitment failures in which very few individuals survive their first year after metamorphosis (Pope et al., 2014), suggesting that juveniles are particularly vulnerable. Here, we document a dramatic decline in juvenile $R$. cascadae at a lake in northern California and show that this decline may have been linked to the emergence of a hypervirulent, highly immunotoxic strain of $B d$.

\section{Materials and methods}

Host-pathogen dynamics in the field

We evaluated $R$. cascadae population size, $B d$ prevalence and $B d$ infection intensity at Section Line Lake in the Klamath Mountains and at Carter Meadow in the southern Cascade Mountains (Supplementary Figure S1). Between 2008 and 2013 we measured frog abundance using visual encounter surveys (Crump and Scott, 1994; Pope, 2008). Each site was visited multiple times over the course of each season (except for Section Line in
2012); we used the highest counts of adults and juveniles from a single survey as our abundance estimates for each year (Supplementary Table S1 shows count data from all surveys conducted during the study period). The count data presented in the results were collected under conditions conducive to observing frogs (mostly clear skies, warm air temperatures and patches of sunlight for basking).

We sampled frogs for $B d$ using sterile rayon swabs (Medical Wire and Equipment, Wiltshire, England). Each animal was swabbed five times along the ventral surface of the trunk, five times along the ventral surface of each thigh and five times across each foot. We evaluated the amount of $B d$ on each swab in terms of zoospore equivalents (ZE) using real-time quantitative PCR (Boyle et al., 2004; Hyatt et al., 2007; Retallick et al., 2006; electronic Supplementary Information). $B d$ data was collected between 2008 and 2011. To avoid confounding effects of seasonality, we analyzed $B d$ data collected between late July and early September.

We tested for differences in $B d$ prevalence between the study sites using mixed logistic regression. $B d$ presence/absence on each frog swabbed ( 1 vs 0 ) was the response variable, study site, life stage and year (and the site-year interaction) were fixed predictors, and individual animal was used as a random effect to account for non-independence of observations from the same individual (see electronic Supplementary Material). In 2009-2011 we tested for differences between the two study sites in infection intensity for animals that tested positive for $B d$ (infection intensity data were not available from the 2008 surveys). We used analysis of variance (ANOVA) and applied the same fixed predictor variables as in the analysis of $B d$ prevalence. Few individuals were resampled in the load data set, so we used only one data point for each animal. Infection intensity data were log-transformed to meet ANOVA assumptions.

\section{Laboratory exposure experiment}

We used a laboratory experiment to test for differences in virulence between $B d$ isolated from Section Line Lake and Carter Meadow and to test for variation in the susceptibility of $R$. cascadae. In 2011, we isolated $B d$ from $R$. cascadae collected at Carter Meadow and Section Line Lake and collected $R$. cascadae eggs from five locations (Supplementary Table S3, Supplementary Figure S1). Frogs from each site were reared separately in a standardized environment. After metamorphosis frogs from each site were exposed to each of the two $B d$ isolates, or given sham 'control' exposures, in a fully crossed design. Frog survivorship and $B d$ infection intensity were then monitored for 14 weeks (see electronic Supplementary Material for details).

We evaluated the effect of $B d$ treatment and frog collection site on frog survival using Cox's proportional hazard model. To test for effects of $B d$ 
treatment and frog collection site on $B d$ prevalence and infection intensity in living frogs, we used mixed models. These $B d$ analyses were conducted using data from the first 2 weeks of the experiment, as there were sharp increases in mortality in some of the treatment groups after that point. Thus, the results provide insight into the rate of $B d$ prevalence and infection intensity increase prior to the onset of $B d$-related mortality. $B d$ isolate, frog origin and week after exposure (week 1 or 2) were fixed predictors, and frog identity was included as a random factor to account for the non-independence of measurements taken from the same animal. Prevalence was analyzed using mixed logistic regression. Infection intensity in $B d$-positive animals was analyzed using a linear mixed model. Number of ZEs was log-transformed to meet assumptions of normality.

\section{$B d$ growth in vitro}

We characterized the growth of three $B d$ isolates in liquid culture. In addition to the isolates from Section Line Lake and Carter Meadow, we tested an isolate collected from a bullfrog (Lithobates catesbiana) at Finley Lake (in the foothills of the Cascade Mountains in northern California) in 2011. Cultures were started with 10000 zoospores and grown in 96-well plates with 10 wells per isolate and 36 negative controls per plate. There were 30 replicate cultures of each isolate. Cultures were grown at room temperature $\left(23^{\circ} \mathrm{C}\right)$ and absorbance values were read daily at $490 \mathrm{~nm}$ using a PowerWaveXS Microplate reader (BioTek, Bath, UK). This experiment was run twice.

To characterize the growth of $B d$, we fit logistic growth models to absorbance data. This model has three parameters: $r$ or intrinsic growth rate; $K$ or carrying capacity and $a$ or initial size. A separate logistic model was fit for replicate cultures of each isolate on each plate, giving a total of 18 sets of parameter estimates ( 2 experiments $\times 3$ plates $\times 3 \mathrm{Bd}$ isolates). The first 3 days of each experiment were not used in model fitting, as minimal growth was observed during this period. Parameter estimates from logistic model fits were evaluated using a mixed-model ANOVA, with $B d$ isolate as a fixed effect and experiment and plate as random effects (plate was removed if it did not explain significant variation). Logistic models were fit using the nls function in R (R Development Core Team, 2012) and mixed models were fit using the lme4 package (Bates et al., 2014).

\section{Immunotoxicity assay}

We tested four $B d$ isolates for immunotoxicity. In addition to isolates from Section Line Lake, Carter Meadow and Finley Lake, we also assayed the type isolate JEL197, originally isolated by Longcore et al., 1999 from Dendrobates auratus. Jurkat cells (from an immortalized line of human $\mathrm{T}$ lymphocytes) were used as a surrogate for amphibian lymphocytes. The toxicity of $B d$ isolates against amphibian lymphocytes has been very thoroughly documented (Fites et al., 2013). In the same paper, sensitivity of human and mouse lymphocytes was also documented. Thus, lymphocytes from multiple species are sensitive to the virulence factors released by $B d$. The use of Jurkat cells provided a standardized target population and avoided possible genetic variability due to the use of outbred frog lymphocytes. To assess the extent to which $B d$ isolates inhibit the growth of Jurkat T cells, Jurkat cells were plated at 200000 per well $\left(1 \times 10^{6} \mathrm{ml}^{-1}\right)$ and zoospores were added at a final concentration of $1 \times 10^{6}$ per well $\left(5 \times 10^{6} \mathrm{ml}^{-1}\right)$, with four to seven replicate wells per treatment in each assay. One control featured Jurkat cells only and the other control contained the DNA inhibitor etoposide (at $25 \mu \mathrm{g} \mathrm{ml}^{-1}$ ). After 2 days, the cultures were pulsed with $0.5 \mu \mathrm{Ci}{ }^{3} \mathrm{H}$-thymidine $(5 \mu \mathrm{Ciml})^{-1}$, specific activity $2 \mathrm{Ci} \mathrm{mmol}^{-1}$; Perkin Elmer, Waltham, MA, USA) and harvested on the third day. Proliferation was quantified at counts per minute using a Wallac 1205 Betaplate Beta Liquid Scintillation Counter (Perkin Elmer).

Eleven assays were run, but not all treatments were included in each; each treatment was included in nine assays (Supplementary Table S6). For each assay, we found the mean counts per minute for each treatment and used these to calculate the degree of inhibition of Jurkat cell proliferation. We evaluated the difference between treatments in the degree of inhibition using mixed-model ANOVA. Treatment was used as a fixed effect and assay was a random blocking factor.

\section{Genome sequencing}

We extracted genomic DNA from cultures of the Section Line isolate and the Carter Meadow isolate that had undergone 10 laboratory passages. Prior to DNA extraction, we cultured the isolates for 5 days on two replicate $1 \%$ tryptone and $1 \%$ agar plates. We flooded the plates for zoospores and concentrated zoospores using a tabletop centrifuge. We extracted genomic DNA using a phenol-chloroform protocol (Zolan and Pukkila, 1986) modified for use in $B d$ (Joneson et al., 2011). The Section Line and Carter Meadow genomes were sequenced using the Illumina MiSeq platform $(2 \times 250 \mathrm{bp}$ paired end reads) at the University of Idaho's Genomics Resources Core Facility. Sequence data have been contributed to the NCBI SRA (accession SRP049423).

Sequence alignment and single nucleotide polymorphism calling were performed as in the study by Rosenblum et al. (2013). We inferred phylogenetic relationships among isolates using a parsimony method, predicted genomic regions affected by past 'loss-of-heterozygosity' (LOH) events and estimated supercontig copy numbers using single nucleotide polymorphism allele frequencies (Rosenblum et al., 
2013; electronic Supplementary Material). We also assessed protease gene distribution across the 19 largest $B d$ contigs; we included three $B d$ protease families (metallo-, serine-type and aspartyl proteases) previously characterized in the study by Joneson et al. (2011).

To test for adaptive genomic evolution in the Section Line isolate, we used the sequence divergence test $\mathrm{d} N / \mathrm{d} S$ and scanned for genes with an excess of nonsynonymous $(\mathrm{d} N)$ relative to synonymous (dS) substitutions in heterozygous single nucleotide polymorphisms. We used the Yang and Nielsen method (yn00) in PAML 4.6 (Yang, 2007) to calculate the pair-wise ratio of nonsynonymous substitution rate/synonymous substitution rate for each gene in the Section Line isolate compared with a basal isolate, UM142. Positive selection on a gene is indicated if the $\mathrm{d} N / \mathrm{d} S$ ratio for that gene is $>1$.

\section{Ethics statement}

This study was performed in strict accordance with the Public Health Service Policy on Humane Care and Use of Laboratory Animals. The protocol was approved by the University of California, Davis Institutional Animal Care and Use Committee (Protocol \#16444).

\section{Results}

\section{Field host/pathogen dynamics}

At Section Line Lake, the abundance of juvenile frogs declined by >99\% between 2009 and 2012; adult abundance increased steadily between 2008 and 2012, then declined sharply between 2012 and 2013 (Figure 1). The abundance of adults and juveniles at Carter Meadow was much lower than the maxima achieved at Section Line Lake, and there were no consistent declining trends (Figure 1). $B d$ prevalence was about five times higher at Section Line Lake (0.61: 98/161) than at Carter Meadow (0.12: 19/156) between 2008 and 2011 (Supplementary Table S2; $\left.\chi^{2}=137.7, P<0.0001\right)$. For animals that tested positive for $B d$, infection intensity was almost seven times higher at Section Line (mean: 3528 ZE) Lake than Carter Meadow (mean: 535 ZE) over the course of the study (Supplementary Table S2; $F_{1,96}=91.8, P<0.0001$ ). There were significant differences between years in both prevalence $\left(\chi^{2}=72.5, P<0.0001\right)$ and infection intensity $\left(F_{2,96}=14.0, P<0.0001\right)$, and there was also a significant site $\times$ year interaction for infection intensity $\left(F_{2,94}=44.2, P<0.0001\right)$. Our analyses did not uncover statistical associations between life stage and $B d$ prevalence or infection intensity.

\section{Laboratory experiment}

To assess the virulence of $B d$ isolates collected from Section Line Lake and Carter Meadow, we conducted controlled laboratory exposures of 171 fieldcollected, captive-reared $R$. cascadae from five source

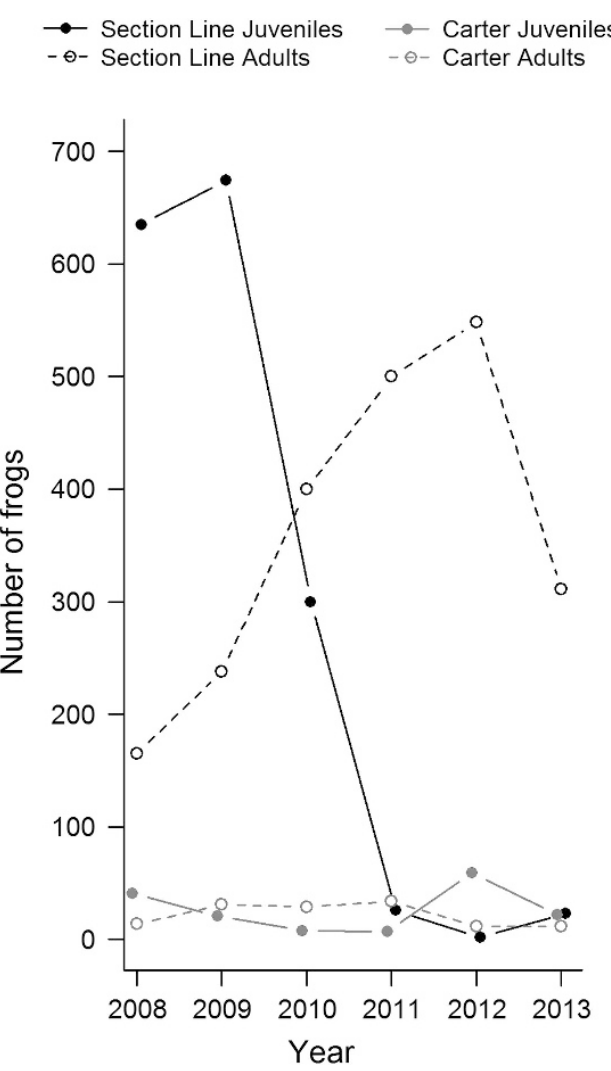

Figure 1 Rana cascadae population trends at Section Line Lake and Carter Meadow. The maximum number of adult and juvenile frogs observed during visual encounter surveys is shown.

populations (Supplementary Table S3). Over the course of the experiment $95 \%$ of the 56 frogs exposed to Section Line $B d$ died or had to be killed (with most mortality occurring 15-40 days after exposure), compared with $33 \%$ of the 57 frogs exposed to Carter Meadow $B d$ and 14\% of the 58 control frogs (Figure 2; $B d$ strain effect: $\left.\chi^{2}=121.34, P<0.0001\right)$; significant differences between all three treatments were confirmed with post-hoc Tukey tests.

Infection dynamics also differed between $B d$ isolates. In the first week after exposure, $B d$ prevalence was $80 \%$ higher in animals exposed to Section Line $B d$ than in animals exposed to Carter Meadow $B d$; on week $2 B d$ prevalence was $>150 \%$ higher in the Section Line $B d$ treatment (Supplementary Figure S2; Supplementary Table S4; $B d$ strain $\times$ week interaction: $\left.\chi^{2}=13.65, P<0.001\right)$. For animals that tested positive for $B d$, the average infection intensity on animals exposed to Section Line $B d$ increased from 218 to $60916 \mathrm{ZE}$ between weeks 1 and 2 after exposure, while the average infection intensity on animals exposed to Carter Meadow $B d$ was substantially lower-about $67 \mathrm{ZE}$ in week 1 and $254 \mathrm{ZE}$ in week 2 (Supplementary Figure S2; Supplementary Table S4; Bd strain $\times$ week interaction: $\left.\chi^{2}=36.04, P<0.0001\right)$.

We did not detect differences in survivorship between the five source populations (Supplementary Table S4). However, Bd prevalence and infection 


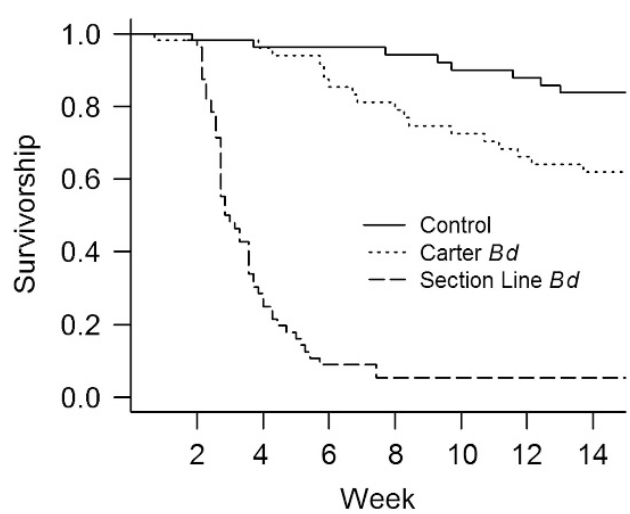

Figure 2 Survival of Rana cascadae metamorphs in a laboratory virulence assay. Frogs were exposed to $B d$ isolated from Carter Meadow $(n=57), B d$ isolated from Section Line Lake $(n=56)$ and a control treatment containing no $B d$ zoospores $(n=58)$ in the laboratory.

intensity differed between frog populations during the first 2 weeks of the experiment (Supplementary Table S4)—Tukey tests indicated that frogs from Old Cow Creek experienced higher prevalence than frogs from two of the four other collection sites, and higher infection intensity than all other populations (except for individuals exposed to $B d$ from Carter Meadow, for which there were no differences between populations). Frogs from Old Cow Creek differed from frogs from the other four source populations in that they were larger in size (length ANOVA: $F_{4,161}=42.41$; $P<0.0001)$ and were exposed to a different preparation of the $B d$ inocula, because they matured about 1 month prior to frogs from the other sites (electronic Supplementary Material, Supplementary Table S3).

\section{Bd phenotype}

The Section Line $B d$ isolate had a lower instrinsic growth rate $(r)$, but a higher carrying capacity $(K)$ in liquid medium than two other northern California $B d$ isolates, Carter Meadow and Finley Lake (Supplementary Table S5, Supplementary Figure S3). Immunotoxicity assays showed that the Section Line $B d$ isolate inhibited T-lymphocyte (Jurkat cell) growth $\sim 22 \%$ more than the two other northern California $B d$ isolates; it was also more inhibitory than the type isolate for $B d$ (JEL197), which has been in continuous culture in the Rollins-Smith lab since about 1999 (treatment effect: $F_{4,31.9}=15.23$, $P<0.0001$; Supplementary Figure S4). In fact, the Section Line $B d$ isolate decreased Jurkat cell proliferation as much as the cytotoxic DNA synthesis inhibitor etoposide (used as a control).

\section{Genomic analyses}

Our genomics results are based on 13696 single nucleotide polymorphisms across 17 supercontigs. We obtained a depth of coverage for aligned reads of $26 \times$ in Section line and $3 \times$ in Carter Meadow. We included both isolates in all subsequent analyses, but focus more directly on the Section line isolate because this isolate has the most interesting virulence phenotype and the most robust genomic coverage. Using a phylogeny that included 29 isolates from a previous study (Rosenblum et al., 2013), we found that the Section Line and Carter Meadow isolates nested (with high bootstrap support) within the most recently derived and widely distributed clade-the GPL (Supplementary Figure S5). Although the isolates were found in a subclade that includes some other California isolates, there was little geographic signature within the GPL, and close relatives were collected from many localities in North and South America.

The most compelling genomic patterns observed were chromosomal copy number variation and $\mathrm{LOH}$ in the Section Line isolate. Chromosomal copy number for the Section Line and Carter Meadow isolates varied from disomic to pentasomic and disomic to tetrasomic, respectively. Most notably, the Section line isolate showed an increase in copy number for 7 of 17 supercontigs when compared with the mean copy numbers of 29 isolates from a previous study (Rosenblum et al., 2013; Supplementary Figure S6). Specifically, supercontigs 2, 3, 7, 8, 11, 12 and 14 showed higher copy numbers in the Section Line isolate than the average of other isolates studied to date. The genomic patterns of LOH for Section Line and Carter Meadow were generally within the range of variation observed in other isolates. However, Section Line contained three chromosomes (7,8 and 15) that appeared to be affected by $\mathrm{LOH}$ events spanning the complete length of the chromosome. Only one of 1336 genes evaluated showed a $\mathrm{d} N / \mathrm{d} S$ ratio $>1$ and it was a gene coding for an uncharacterized predicted protein.

\section{Discussion}

$B d$ has caused declines and extinctions in amphibians worldwide, but remarkably little is known about why this pathogen has catastrophic effects on some populations of susceptible hosts and not on others. We documented a dramatic decline in a montane amphibian population and used a laboratory experiment to show that $B d$ isolated in the midst of this decline was markedly more virulent than $B d$ isolated in the same year from a population of the same amphibian host that did not experience a dramatic decline during the same period. We then assessed phenotypic and genomic correlates of virulence for both strains and found that the highly virulent isolate exhibited greater immunotoxicity than other $B d$ isolates from northern California and attained higher optical densities in liquid culture. Both isolates were nested solidly within the GPL, and there was some evidence that the more virulent isolate experienced more rapid genomic evolution 
than other GPL isolates. These findings suggest that a particularly virulent strain of $B d$ was responsible (at least in part) for a dramatic host decline, and highlight phenotypic and genomic characteristics of the pathogen that may be linked to this event.

Phenotypic characteristics that have been linked to virulence in $B d$ include immunotoxicity (Fites et al., 2013) and traits associated with growth, such as zoospore production (Langhammer et al., 2013) and zoosporangium size (Fisher et al., 2009a). With regard to immunotoxicity, the Section Line $B d$ isolate inhibited the growth of human immune cells more than other northern California $B d$ isolates; Fites et al., (2013) showed that Bd has similar toxicity to amphibian, mouse and human lymphocytes. This lends support to the hypothesis that the deleterious effect of $B d$ on host organisms is linked to the pathogen's ability to inhibit critical immune functions, suggesting that enhanced immunotoxicity may drive amphibian declines. The Section Line $B d$ isolate attained a higher optical density but had a lower exponential growth rate in culture than other northern California $B d$ isolates. This finding suggests that the ability to maintain growth at high conspecific density may be an important aspect of $B d$ virulence. This is the first time that optical density at carrying capacity has been linked to virulence; more work needs to be done to determine if this is a general pattern. The results of our in vitro growth experiment were not consistent with the results of our laboratory exposure experiment, as $B d$ loads increased much more rapidly on animals exposed to the Section Line isolate than those exposed to $B d$ from Carter Meadow (Supplementary Figure S2). Thus, it seems that maximum growth rate in culture may not correspond to the rate at which $B d$ density increases on susceptible hosts (as in Raffel et al., 2013), and that care should be taken when using phenotypic characteristics of $B d$ laboratory culture to infer effects on particular host species.

There were also genomic differences between Section Line $B d$ and other $B d$ isolates. Our phylogenetic analysis placed the Section Line isolate within the GPL, which is thought to be responsible for most of the worldwide amphibian declines and extinctions. However, the Section Line isolate was distinguished from other sequenced isolates in the GPL by high rates of polysomy in particular regions of the genome and elevated LOH. Copy number variation and $\mathrm{LOH}$ have been proposed as mechanisms for rapid evolution in Bd (Farrer et al., 2013; Rosenblum et al., 2013). Thus, it is possible that these genomic processes have altered copy number or allele frequencies for genes that relate to virulence. Chromosomal segments that should be targets for future study include 7 and 8 , which show unusual copy number variation and $\mathrm{LOH}$ patterns in the Section Line isolate, and 12, which is found at a high copy number in the Section Line isolate and contains a high density of protease gene copies, that are hypothesized to have a role in $\mathrm{Bd}$ pathogenesis (Rosenblum et al., 2013). Although our genomic analyses highlighted important genomic processes and broad-scale regions of the genome, we did not find evidence for selection on particular genes-ofinterest. Methods to scan for selection in single genomes generally have low power, so additional work is required to understand how the genomic patterns revealed here may relate to specific virulence properties of $B d$.

At Section Line Lake, there was a $>99 \%$ reduction in juvenile abundance between 2009 and 2012. In 2010 juveniles still numbered in hundreds; in July 2011 we observed only 3 juveniles and 16 carcasses (observations of frog carcasses have been extremely rare in thousands of hours of visual survey we performed in this system, so this number of carcasses is quite unusual); only 2 juveniles were seen in our 2012 survey. Adults began to decline 3 years after juveniles, which is consistent with the 35 years of age at maturity observed for this species in this region (Pope et al., 2014). These observations support our contention that high levels of mortality led to the disappearance of most juvenile frogs from this population. High overwinter mortality in juveniles is consistent with declines associated with $B d$, and we did not observe evidence of other causes of recruitment failure or juvenile mortality such as desiccation or elevated levels of predation. Furthermore, $B d$ prevalence and load were relatively high at Section Line Lake during the study period.

It is possible that factors other than elevated pathogen virulence contributed to a $B d$-related juvenile decline at Section Line Lake. For example, environmental factors may have exacerbated the effects of $B d$ on $R$. cascadae at this particular siteat $2182 \mathrm{~m}$, Section Line Lake is near the upper end of the elevation range occupied by $R$. cascadae in California, and $B d$ prevalence can increase with elevation for R. cascadae (Piovia-Scott et al., 2011). In contrast, Carter Meadow is lower in elevation $(1865 \mathrm{~m})$ and features a network of streams and pools, which may be less favorable for the maintenance of $B d$ infections (Pope et al., unpublished data). In addition, the density of frogs at Section Line Lake was quite high (1.2 frogs per meter of shoreline in 2008), having increased dramatically following the removal of introduced trout from this lake in 2003 (Pope, 2008, Pope et al., unpublished data), and theoretical models of interactions between $B d$ and amphibian hosts indicate that high host density can facilitate the buildup of high $B d$ loads and increase host mortality (Briggs et al., 2010). However, a site $18 \mathrm{~km}$ from Section Line Lake at a similar elevation has sustained high frog densities in the presence of $B d$ without experiencing dramatic declines (Piovia-Scott et al., unpublished data), suggesting that high elevation and high frog density do not always lead to epizootic events. Our laboratory experiment suggested that frogs from different source populations differ in the level of 
$B d$ infection they develop, which may indicate that populations differ in their ability to resist infection. However, we found no evidence that frogs from Section Line Lake were more susceptible to $B d$ than frogs from other sites, suggesting that the presence of particularly susceptible host genotypes was not one of the principal drivers of juvenile decline. Finally, it is possible that the hyper-virulent isolate used in our laboratory experiment was not the dominant strain present at Section Line Lake during the decline. However, a second isolate from Section Line Lake collected in 2013 also showed exceptional virulence compared with several other northern California isolates (Piovia-Scott et al., unpublished data), suggesting that the isolate described in the current paper may not represent a rare virulence phenotype. Future research should focus on quantifying the relative importance of pathogen virulence, abiotic environmental factors and host density as drivers of $B d$-related amphibian declines and on evaluating within-population variation in $B d$ virulence.

Why does the Section Line $B d$ isolate exhibit high virulence? Exponential host population growth and high host density have been linked to the in situ evolution of increased virulence (Bull, 1994; Ewald, 1994; Lenski and May, 1994), and these conditions were present at Section Line Lake shortly before the isolate was collected. The low virulence of $B d$ from the smaller and more stable Carter Meadow population is consistent with the expectation that reduced virulence can emerge in low density populations (Bull, 1994; Ewald, 1994; Ebert and Bull, 2008). Unfortunately, the rapid course of $B d$-related mortality in some montane amphibians may mean that many populations go extinct before reduced virulence can evolve (Vredenburg et al., 2010). Alternatively, $B d$ virulence at a site may be driven largely by dispersal and gene flow (that is, the characteristics of propagules that colonize the site), rather than within-site selective forces. For example, the virulence of $B d$ may increase as the pathogen spreads across a previously unoccupied landscape (Phillips and Puschendorf, 2013). However, recent surveys of the study region did not uncover any evidence of an invasion front (Piovia-Scott et al., 2011; Pope et al., 2014), and the absence of detailed information on the introduction and spread of $B d$ in northern California makes it difficult to ascertain whether high virulence of the Section Line isolate is likely to be a product of invasion history in this region. More regional-scale population genetic studies (for example, Rodriguez et al., 2014) are needed to outline the processes driving variation in $B d$ virulence across landscapes.

In summary, this study expands our understanding of virulence in a devastating pathogen by providing clear links between putative virulence factors (for example, immunotoxicity), rigorous virulence assays and a specific host decline. Interestingly, the high-virulence isolate was collected in a region where the host amphibian is widespread (Piovia-Scott et al., 2011), while the low-virulence isolate came from a remnant population in a region where dramatic host declines have occurred (Fellers et al., 2008). This inconsistency between sitespecific host-pathogen interactions and regional patterns of host decline highlights the importance of local processes in determining host-pathogen dynamics and the continued potential for disease outbreaks in populations that appear to be persisting with a pathogen.

\section{Conflict of Interest}

The authors declare no conflict of interest.

\section{Acknowledgements}

Monty Larson, Kevin Aceituno and Cathy Johnson and many others helped in field data collection; Carlos Davidson and Daniella Reagan helped with the amphibian experiment. This research was supported by grants from the California Department of Fish and Wildlife, the United States Fish and Wildlife Service, Lassen National Forest and the National Science Foundation (IOS-1121758 and IOS-12244804).

\section{References}

Adams MJ, Chelgren ND, Reinitz D, Cole RA, Rachowicz LJ, Galvan S et al. (2010). Using occupancy models to understand the distribution of an amphibian pathogen Batrachochytrium dendrobatidis. Ecol Appl 20: 289-302.

Bates D, Maechler M, Bolker B. (2014). lme4: Linear mixedeffects models using Eigen and S4. Available from http:// cran.r-project.org/web/packages/lme4/index.html.

Berger L, Speare R, Daszak P, Green DE, Cunningham AA, Goggin CL et al. (1998). Chytridiomycosis causes amphibian mortality associated with population declines in the rain forests of Australia and Central America. Proc Natl Acad Sci USA 95: 9031-9036.

Berger L, Marantelli G, Skerratt LL, Speare R. (2005). Virulence of the amphibian chytrid fungus Batrachochytrium dendrobatidis varies with the strain. Dis Aquat Organ 68: 47-50.

Boyle DG, Boyle DB, Olsen V, Morgan JA, Hyatt AD. (2004). Rapid quantitative detection of chytridiomycosis (Batrachochytrium dendrobatidis) in amphibian samples using real-time Taqman PCR assay. Dis Aquat Organ 60: 141-148.

Briggs CJ, Knapp RA, Vredenburg VT. (2010). Enzootic and epizootic dynamics of the chytrid fungal pathogen of amphibians. Proc Natl Acad Sci USA 107: 9695-9700.

Bull JJ. (1994). Perspective: virulence. Evolution 48: 1423-1437.

Crump ML, Scott NJJ. (1994). Standard techniques for inventory and monitoring: visual encounter surveys. In: Heyer WR, Donnelly MA, McDiarmid RW, Hayek LC, Foster MS (eds) Measuring and Monitoring Biological Diversity: Standard Methods for Amphibians. Smithsonian Institution: Washington, D.C., USA, pp 84-92. 
Ebert D, Bull JJ. (2008). The evolution and expression of virulence. In: Stearns SC, Koella JC (eds) Evolution in Health and Disease, 2nd edn. Oxford. University Press: New York, NY, USA, pp 154-167.

Ewald PW. (1994). Evolution of Infectious Disease. Oxford University Press: New York, NY, USA.

Farrer RA, Weinert LA, Bielby J, Garner TJ, Balloux F, Clare $\mathrm{F}$ et al. (2011). Multiple emergences of genetically diverse amphibian-infecting chytrids include a gobalized hypervirulent recombinant lineage. Proc Natl Acad Sci USA 108: 18732-18736.

Farrer RA, Henk DA, Garner TWJ, Balloux F, Woodhams DC, Fisher MC. (2013). Chromosomal copy number variation, selection and uneven rates of recombination reveal cryptic genome diversity linked to pathogenicity. PLoS Genet 9: e1003703.

Fellers GM, Pope KL, Stead JE, Koo MS, Welsh HH. (2008). Turning population trend monitoring into active conservation: can we save the Cascades frog (Rana Cascadae) in the Lassen region of California? Herpetol Conserv Bio 3: 28-39.

Fisher MC, Bosch J, Yin Z, Stead DA, Walker J, Selway L et al. (2009a). Proteomic and phenotypic profiling of the amphibian pathogen Batrachochytrium dendrobatidis shows that genotype is linked to virulence. Mol Ecol 18: $415-429$.

Fisher MC, Garner TWJ, Walker SF. (2009b). Global emergence of Batrachochytrium dendrobatidis and amphibian chytridiomycosis in space, time, and host. Annu Rev Microbiol 63: 291-310.

Fites JS, Ramsey JP, Holden WM, Collier SP, Sutherland DM, Reinert LK et al. (2013). The invasive chytrid fungus of amphibians paralyzes lymphocyte responses. Science 342: 366-369.

Gahl MK, Longcore JE, Houlahan JE. (2012). Varying responses of northeastern North American amphibians to the chytrid pathogen Batrachochytrium dendrobatidis. Conserv Biol 26: 135-141.

Garcia TS, Romansic JM, Blaustein AR. (2006). Survival of three species of anuran metamorphs exposed to UV-B radiation and the pathogenic fungus Batrachochytrium dendrobatidis. Dis Aquat Organ 72: 163-169.

Hyatt AD, Boyle DG, Olsen V, Boyle DB, Berger L, Obendorf D et al. (2007). Diagnostic assays and sampling protocols for the detection of Batrachochytrium dendrobatidis. Dis Aquat Organ 73: 175-192.

Joneson S, Stajich JE, Shiu SH, Rosenblum EB. (2011). Genomic transition to pathogenicity in chytrid fungi. PLoS Pathogens 7: e1002338.

Kilpatrick AM, Briggs CJ, Daszak P. (2010). The ecology and impact of chytridiomycosis: an emerging disease of amphibians. Trends Ecol Evol 25: 109-118.

Kriger KM, Pereoglou F, Hero JM. (2007). Latitudinal variation in the prevalence and intensity of chytrid (Batrachochytrium dendrobatidis) infection in eastern Australia. Conserv Biol 21: 1280-1290.

LaDeau SL, Kilpatrick AM, Marra PP. (2007). West Nile virus emergence and large-scale declines of North American bird populations. Nature 447: 710-U713.

Langhammer PF, Lips KR, Burrowes PA, Tunstall T, Palmer CM, Collins JP. (2013). A fungal pathogen of amphibians, Batrachochytrium dendrobatidis, attenuates in pathogenicity with in vitro passages. PLoS One 8: e77630.

Lenski RE, May RM. (1994). The evolution of virulence in parasites and pathogens: Reconciliation between two competing hypotheses. J Theor Biol 169: 253-165.
Lips KR, Brem F, Brenes R, Reeve JD, Alford RA, Voyles J et al. (2006). Emerging infectious disease and the loss of biodiversity in a Neotropical amphibian community. Proc Natl Acad Sci USA 103: 3165-3170.

Lipsitch M, Cohen T, Cooper B, Robins JM, Ma S, James L et al. (2003). Transmission dynamics and control of severe acute respiratory syndrome. Science $\mathbf{3 0 0}$ : 1966-1970.

Longcore JE, Pessier AP, Nichols DK. (1999). Batrachochytrium dendrobatidis gen et $\mathrm{sp}$ nov, a chytrid pathogenic to amphibians. Mycologia 91: 219-227.

Pearl CA, Adams MJ, Bury RB, Wente WH, McCreary B. (2009). Evaluating amphibian declines with site revisits and occupancy models: status of montane anurans in the Pacific northwest USA. Diversity 1: 166-181.

Phillips BL, Puschendorf R. (2013). Do pathogens become more virulent as they spread? Evidence from the amphibian declines in Central America. Proc $R$ Soc $B$ Biol Sci 280: 20131290.

Piovia-Scott J, Pope KL, Lawler SP, Cole EM, Foley JE. (2011). Factors related to the distribution and prevalence of the fungal pathogen Batrachochytrium dendrobatidis in Rana cascadae and other amphibians in the Klamath Mountains. Biol Conserv 144: 2913-2921.

Pope KL. (2008). Assessing changes in amphibian population dynamics following experimental manipulations of introduced fish. Conserv Biol 22: 1572-1581.

Pope KL, Brown C, Hayes M, Green G, Macfarlane D. (2014). Cascades Frog Conservation Assessment. Pacific Southwest Research Station, United States Forest Service: Albany, CA, USA.

$\mathrm{R}$ Development Core Team (2012). R: A language and environment for statistical computing. R Foundation for Statistical Computing: Vienna, Austria.

Raffel TR, Romansic JM, Halstead NT, McMahon TA, Venesky MD, Rohr JR. (2013). Disease and thermal acclimation in a more variable and unpredictable climate. Nat Clim Change 3: 146-151.

Retallick RW, Miera V, Richards KL, Field KJ, Collins JP. (2006). A non-lethal technique for detecting the chytrid fungus Batrachochytrium dendrobatidis on tadpoles. Dis Aquat Organ 72: 77-85.

Retallick RW, Miera V. (2007). Strain differences in the amphibian chytrid Batrachochytrium dendrobatidis and non-permanent, sub-lethal effects of infection. Dis Aquat Organ 75: 201-207.

Richards-Zawacki CL. (2010). Thermoregulatory behaviour affects prevalence of chytrid fungal infection in a wild population of Panamanian golden frogs. Proc $R$ Soc B 277: 519-528.

Rodriguez D, Becker CG, Pupin NC, Haddad CF, Zamudio KR. (2014). Long-term endemism of two highly divergent lineages of the amphibian-killing fungus in the Atlantic Forest of Brazil. Mol Ecol 23: 774-787.

Rosenblum EB, Poorten TJ, Joneson S, Settles M. (2012). Substrate-specific gene expression in Batrachochytrium dendrobatidis, the chytrid pathogen of amphibians. PLOS ONE 7: e49924.

Rosenblum EB, James TY, Zamudio KR, Poorten TJ, Ilut D, Rodriguez D et al. (2013). Complex history of the amphibian-killing chytrid fungus revealed with genome resequencing data. Proc Natl Acad Sci USA 110: 9385-9390.

Skerratt LF, Berger L, Speare R, Cashins S, McDonald KR, Phillott AD et al. (2007). Spread of chytridiomycosis has caused the rapid global decline and extinction of frogs. Ecohealth 4: 125-134. 
Smith GJ, Vijaykrishna D, Bahl J, Lycett SJ, Worobey M, Pybus OG et al. (2009). Origins and evolutionary genomics of the 2009 swine-origin H1N1 influenza A epidemic. Nature 459: 1122-U1107.

Vredenburg VT, Knapp RA, Tunstall TS, Briggs CJ. (2010). Dynamics of an emerging disease drive large-scale amphibian population extinctions. Proc Natl Acad Sci USA 107: 9689-9694.
Wake DB, Vredenburg VT. (2008). Are we in the midst of the sixth mass extinction? A view from the world of amphibians. Proc Natl Acad Sci USA 105: 11466-11473.

Yang ZH. (2007). PAML 4: phylogenetic analysis by maximum likelihood. Mol Biol Evol 24: 1586-1591.

Zolan ME, Pukkila PJ. (1986). Inheritance of DNA methylation in coprinus-cinereus. Mol Cell Biol 6: 195-200.

Supplementary Information accompanies this paper on The ISME Journal website (http://www.nature.com/ismej) 